\title{
Does Finance Industry Lead Real Economic Activities? Analysis of Industry Networks
}

\author{
Yong-Cheol $\mathrm{Kim}^{1} \&$ Gabjin $\mathrm{Oh}^{2}$ \\ ${ }^{1}$ Lubar School of Business, University of Wisconsin-Milwaukee, Milwaukee, Wisconsin, USA \\ ${ }^{2}$ Division of Business Administration, College of Business, Chosun University, Gwangju, Republic of Korea \\ Correspondence: Yong-Cheol Kim, Lubar School of Business, University of Wisconsin-Milwaukee, PO Box 742, \\ Milwaukee, Wisconsin 53201-0742, USA.
}

Received: April 6, 2018

Accepted: May 4, 2018

Online Published: May 10, 2018

doi:10.20849/iref.v2i1.380

URL: https://doi.org/10.20849/iref.v2i1.380

\begin{abstract}
The analysis of network of 30 US industries shows the leading role of finance industry. Following are major findings and observations: 1) we show that leading industry in economy changes over time as the U.S. industry structure changes over time. Finance industry plays a leading role of net information source over the sample period of 1930-2014, and the importance of finance industry starts to dominate from 1975. 2) Even when finance industry is not ranked as the strongest source of information, the finance industry dominates in the industry network when the net information flows are adjusted by the value added of finance in the GDP. 3) Differences of strength of directed connectedness (ASDC) of source and sink industries signal potential disturbance in the network of industries.
\end{abstract}

Keywords: industry network, financial crisis, assymetric information flows, variance decomposition

\section{Introduction}

Financial sectors play important roles and functions in the economy, and the share of financial sectors in the economy increases over time and across the global economy. The Great Recession in 2007-2008 evolved through many stages and phases of "financial" crisis. No matter how big and significant the financial sector is in the economy, the crisis is not isolated in the financial sector. The interactions of financial and real sectors and the spread of difficulties and problems in the financial sector to the rest of economic segments create "economic recession". While academics and policy makers recognize the importance of financial sector, the significance of financial sector in the economy, and the interactions of financial sector with the rest of the industries are still in early stage of research.

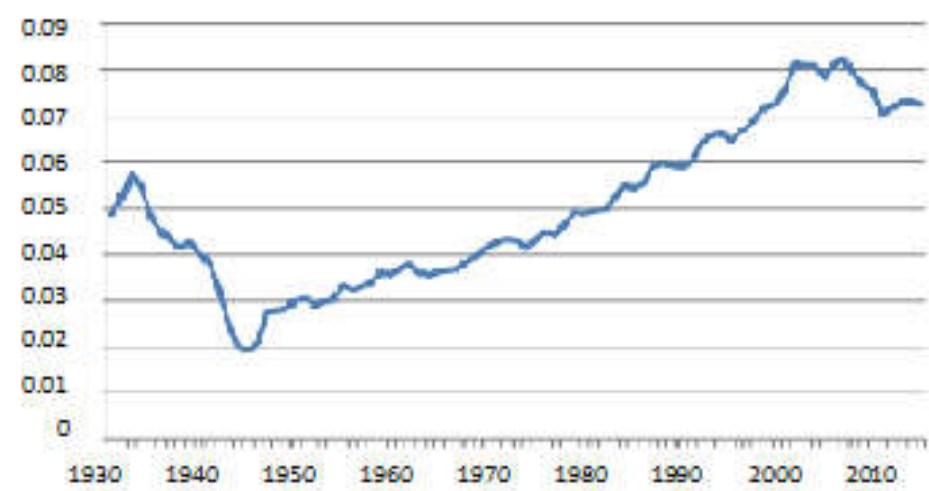

Figure 1. Finance and insurance industry income share of GDP

Description: Finance income share of GDP. Finance Income is the domestic income of the finance and insurance industries, i.e., aggregate income minus net exports. Ending year is 2014.

Source: North American Industry Classification System (NAICS) Association. 
The 2008 financial crisis generated keen interests on the importance and critical role of financial industry in the economy. Philippon (2015) documents the finance industry's share of GDP increases mainly by increasing the quantity of intermediated assets that have direct impact on the secular changes of firms and households from 1980. The interconnectedness is one of key elements that plays central role in creating systemic risk. "System-ic" risk is the risk that creates potential collapse of the system. Billio et al. (2012) analyze systemic risk in financial sectors that consist of four financial institutions-banks, hedge fund, insurance and brokerage firms. Henderson, et al. (2015) show the financial risk in a financial system where financial institution create commodity index fund and commodity linked notes. Chemla and Hennessy (2014) investigate the mortgage market and securitization of mortgage financing in a system of bank-household-investors. Chemla and Hennessy (2014) document that US bond issuance accelerated in 2001, peaks in 2007. They show that all securities asset classes-ABS, MBS and CMO (collateralized debt obligations), CMBS and RMBS (commercial and residential mortgage) and nonmortgage (auto, credit card, and student loans) - peaks in 2006. Data on bank-to-bank, bank-to-firm and bank-to-household show detailed transaction information on the business connections.

When we define the entire economy as one system, the empirical research on interconnectedness is limited as there is no detailed and quantifiable information that shows the nature of business connections. As the disruptions and the liquidity problems reached all segments of the economy in the 2007-2009 financial crisis, industry network analysis at the macro level is warranted. Stock returns are ultimate outcome of information processing by all interested parties. As such, the network of industry index returns is a setup that shed lights on economy- and system-wide connectedness. We use variance decomposition method (VDM) in a network of 30 industries, and estimate the strengths and direction of information flows between and among industries following Diebold and Yilmaz (2014).

Section 2 shows the dominance of finance industries in the economy. Empirical analysis of industry networks is discussed with data and methodology in section 3. Section 4 shows comparison and contrast of ASDC with other business activities. Section 5 concludes.

\section{Dominance of Finance Industries in the Economy}

Philippon (2015) shows that the increasing role of financial industry has the same trend as the increasing quantity of intermediated assets. Securitization and financialization are processes to make cash flow streams between real assets into financial claims. Asset-backed securities and other financial securities based on cash flow claims from real sectors are created by financial institutions to meet the specific needs and demands of various investors. Financialization is a term that describes an economic system or process that attempts to reduce all value that is exchanged (whether tangible, intangible, future or present promises, etc.) into financial instruments. The original intent of financialization is to be able to reduce any work-product or service to an exchangeable financial instrument, like currency, and thus make it easier for wide range of investors (pension funds, institutional funds, etc.) to trade these financial instruments.

Financial products are created and revoked easily as the financial products are simply contracts that specify the characters of cash flows and incumbent liabilities. In contrast, the creation of new products in industrial sectors takes time, sometimes years to implement and produce new products. Kydland and Prescott (1982) recognized the "time to build" for physical capital. As such, once there are disturbances and shocks in industrial and real sectors, it is detrimental as the recovery in real sectors takes long periods to adjust and restructure. Table 1 shows that service, wholesale, smoke, coal and mining industries are major sink industries, and they are adaptable with relatively lower cost of reshuffling.

U.S. Bureau of Economic Analysis (BEA) data shows that the value Added of Finance, insurance, real estate, rental, and leasing is about $20 \%$ for the period of $1997-2014$. The breakdown of $20 \%$ is as follows: Finance and insurance $7 \%$, and Real estate and rental and leasing $13 \%$. While there is no exact match in the industry classification between our industry and BEA industry categories, the significance and importance of finance industry in general is more than what the ranking table indicates as firms in other industry engage in financial transactions (e.g., GMAC). 


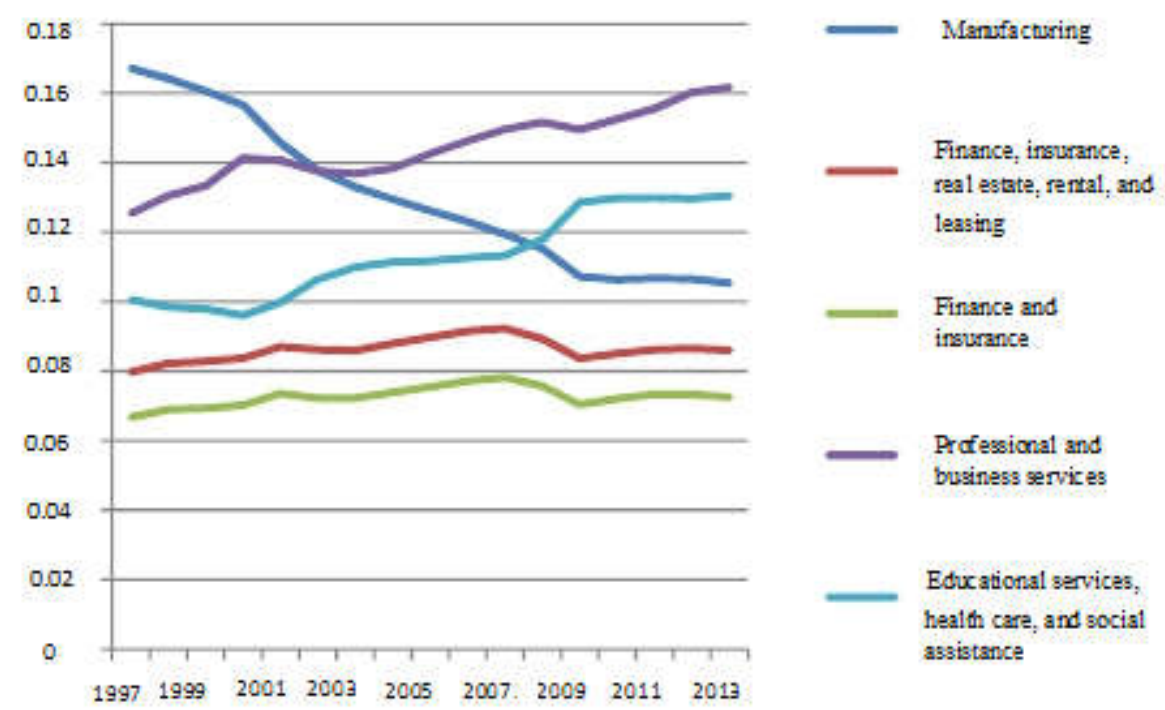

Figure 2. Income share/GDP by industry

Source: Philippon (2015).

Another measure of increasing share of finance industry comes from income share of finance and insurance industry in the GDP. The current share of finance is about $8 \%$ of GDP relative to about $4 \%$ in 1940 's. Figure 2 shows the trend of income share by each industry. Noticeable changes are the decline of income share of manufacturing from $16.7 \%$ in 1997 to $10.5 \%$ in 2013, and the increasing share of two service industries-professional and business service as well as Educational services, health care, and social assistance. Finance industry in a broad measure (including Finance, insurance, real estate, rental, and leasing) or narrow measure (including Finance and insurance) increased over the same period. Broad measure of finance industry changed from $8.0 \%$ in 1997 , reached a peak at $9.2 \%$ in 2007 and declined to $8.6 \%$ in 2013.

Finance industry, as intermediaries of capital, do have connections with all industries and firms, including firms in its own industry. As such, dominance of financial industries would have economy wide implications. For example, increases in the subprime mortgage loans boost housing price, and lead to constructions of new houses. In turn, all industries in the supply chain are going to accelerate its growth. The increase in the consumption by homeowners will have chain effects on the entire economy. The comprehensive understandings of industry network structure and workings of the industry network would provide comprehensive picture on the economic and financial stability and systemic risks.

\section{Empirical Analysis of Industry Networks}

\subsection{Data and Methodology of Network Analysis}

Viewing the economy as evolving industry networks, the analyses of information flows in a network of industries in a system of stock markets shed light on the stability and systemic risk of the economy. The interconnectedness of industries is construed as multi-source multi-sink networks where many information sources are to be multicast to certain sets of destinations (sinks). The information flows are estimated from the industry sector returns. The industry daily return is from the original French 30 -indutry daily return data. The description of the 30 industries is attached in the Appendix 1 (Note 1). Following Diebold and Yilmaz (2014), we estimate the connectedness and information flows among 30 industries from the weighted and directed networks of 30 industries. In addition, to capture time-varying connectedness, we measure the VDM using daily industry returns on a rolling window each trading day. For the main results we estimate forecasting error from VAR with predictive horizon of 12 days, and use variance decomposition as a measure of information flows between 30 industries. Detailed methodology is described in the Appendix. The tables and Appendix discussed in the main text are available from authors upon request.

\subsection{Inter-industry Average Information Flows}

When we define the entire economy as one system, the empirical research on interconnectedness is limited as there is no quantifiable transaction data that shows the details of business connections. As the magnitude of disruptions in the economy that consists of all industries reached all segments of the economy as in the 2008 
financial crisis, network analysis is an appropriate methodology and tools. Stock returns are ultimate outcome of information processing by all interested parties. As such, the network of industry index returns is a setup that shed lights on economy- and system-wide connectedness. We use VDM method in a network of 30 industries, and estimate the weights and direction of information flows between and among industries following Diebold and Yilmaz (2014). We discuss the empirical results with graphs as we are interested in the macro and system-wide changes.

First, we show the average pairwise information flows in 30 industries which is the sum of off-diagonal terms in the VDM matrix. The plot in the Figure 3 shows the strength of connectedness of all industries, on average. Industries are weakly connected in 1955, 1965, 1996 and 2001. When the average information flows as a proxy for stability should decrease with the number of nodes and interactions between them. While average information flows are hovering around 90, there are exceptionally low average information flows (high stability) in 1965, 1996, and 2001. Furthermore, the sharp decrease in the average information flows in 1996, and 2000, and sharp increase in 2001-2003 indicates the rapid changes in the average interconnectedness of industries. High average information flows suggest that economic changes are synchronized and industries and coupled closely with each other.

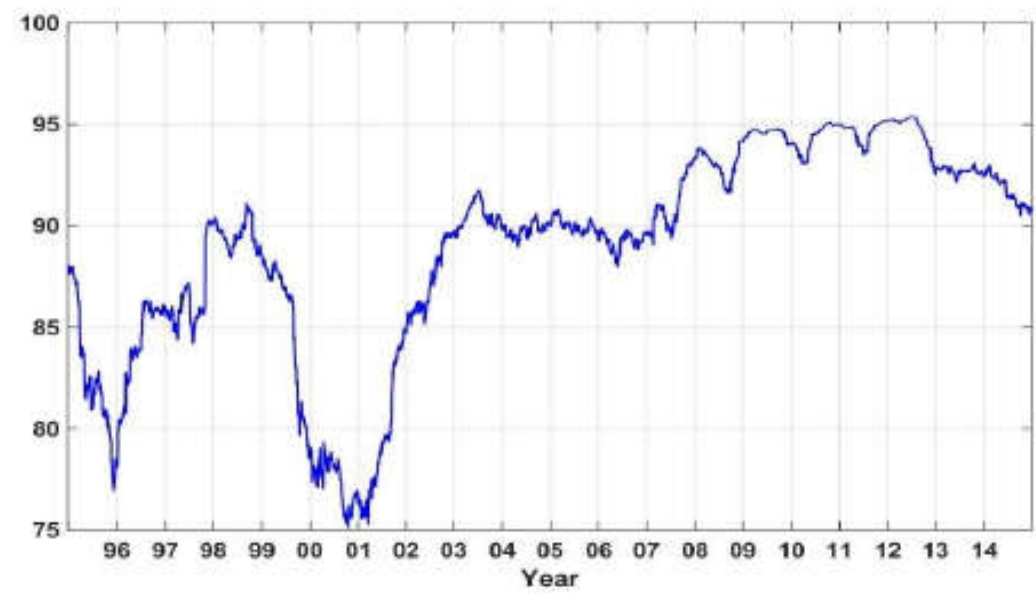

Figure 3. Average information flows based on the strength of connectedness of all industries

\subsection{Asymmetric Information Flows: Network of Source-Sink Industries}

The average information flows are a rough measure of economic stability. However, it ignores the direction and the strength of information flows. We take a network analysis that considers not only the interconnectedness, but also the strength of directed connectedness (SDC) and the asymmetry of SDC (ASDC) between all nodes (industries) in a system.

To investigate in more details about the source-sink relation, we measure the Shannon entropy of both source and sink industries, respectively. Shannon entropy is derived from probability measures of source and sink industries based on the information inflows and outflows. By definitions of source and sink according to the VDM, total sum of source industries is equal to the sum value of sink industries. We identify source and sink industries for each year. All industries are divided into two groups based on the ASDC: the source groups, and the sink groups. ASDC of industry in each group is normalized by the total sum of ASDC. Next, we establish Shannon entropy to estimate the heterogeneity of ASDC defined as follows:

$$
\begin{aligned}
\operatorname{Entrpy}(g) & =-\sum N A S D C g(i) \log N A S D C g(i) \\
N A S D C_{\boldsymbol{g}}(i) & =\frac{A S D C_{\boldsymbol{g}}(i)}{\sum A S D C(i)}, g=\{\text { source }, \sin k\}
\end{aligned}
$$

We use normalized ASDC (NASDC) and the sum of NASDC for each group of source and sink equals to 1. Higher entropy indicates ASDC becomes uniform, i.e., the same amount of information spreads out to multiple 
industries at a given level of entropy. However, as we group source and sink industries separately, the combination of high source entropy and low sink entropy indicates there are multiple source industries and a few sink industries.

In the ranking of industries in each year from the strongest source industries to sink industries, source (sink) industries are the ones that show positive (negative) net information outflows the ranking and strength of information flows are estimated in each year from 1997 to 2014.

There are several notable observations in the network industries over time. From 1975, finance industry is the strongest and very strong source industry in the economy. The years when finance is the strongest source industry are 1997, 1999, 2000, 2003 and 2004. By construction, the numbers in each cell of VDM shows the direction and strength of information flows where positive (negative) signs indicate the net information outflows (inflows), and the sum of rows is zero. Second, the number of industries in the source and sink group changes over time, and certain industries switch from source (sink) to sink (source). Third, the rank of finance industry drops quickly in 2008, and switches to sink in 2009 and 2010. Fourth, the relative strength of information flows of each industry changes over time. For example, the out proportional strength of information for rank one industry is: steel industry at 19.1 in 1945, finance industry at 18.8 in 1999. Fifth, at the opposite end, the relative strength of information for the last rank industry, i.e., out proportional sink industry is: service industry at -68.5 in 1945, mining industry at -63 in 1995, -68 in 1996, and coal industry at -57.5 in 1998.

In the VDM matrix summarizes the weighted and directed connectedness from variance decomposition of 30 industries. It shows how many industries are source industries with positive net information outflows and sink industry with negative net information flows. We estimate the percentage of source industries in terms of number of positive net information flows out of 30 industries. When the percentage of source industries is higher than $50 \%$, i.e., more than half of the industries lead or inversely less than half of industries in the economy bear the brunt of any changes in the source industries. Years 1996, 2003, 2007, 2011 and 2012 are the years when percentage of source industries is over $60 \%$. The numbers between source and sink industries indicate that source industries dominate sink industries. In other words, multiple industries transmit information and that information is borne by smaller number of industries. Using the analogy of soccer game, the offensive team has 6 relative to the defensive team of 4 .

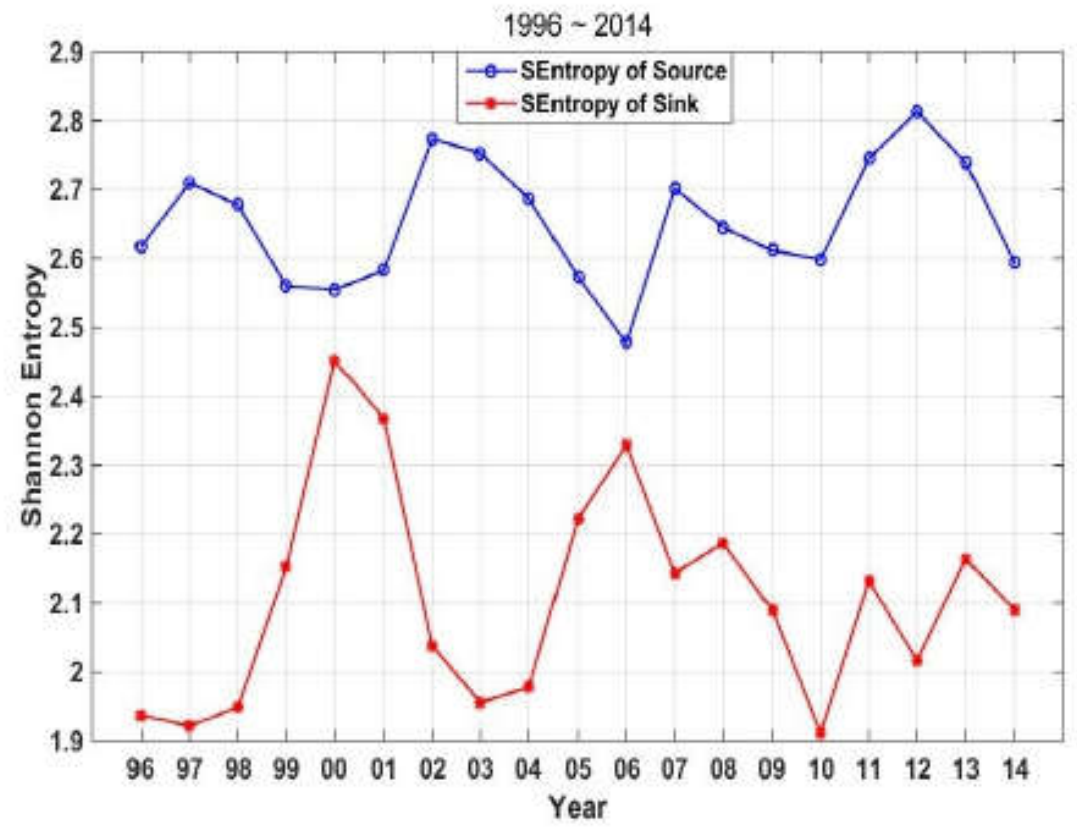

Figure 4. Shannon Entropy in a matrix of Net information flows

While the number of source and sink industries give initial imbalance of the economy, the directed strength of information flows give more precise measures of imbalance. Figure 4 shows the Shannon entropy using the sign and the strength in the VDM to capture strength of directed information flows. Shannon entropy captures the dispersion of the strength of information net flows. The Shannon entropy of source and sink industries are 
measured separately in the Figure 4. The highest imbalance in the strength of information flows between source and sink industries occur in 1997, 2003 and 2012. On the other hand, lowest asymmetry happens in 2000 and 2006. Higher value of ASDC, i.e., large asymmetry of Shannon entropy of source and sink group indicates the dominance of source industries over sink industries in the economy. Differences of Shannon entropy of source and sink industries signal potential disturbance in the network of industries.

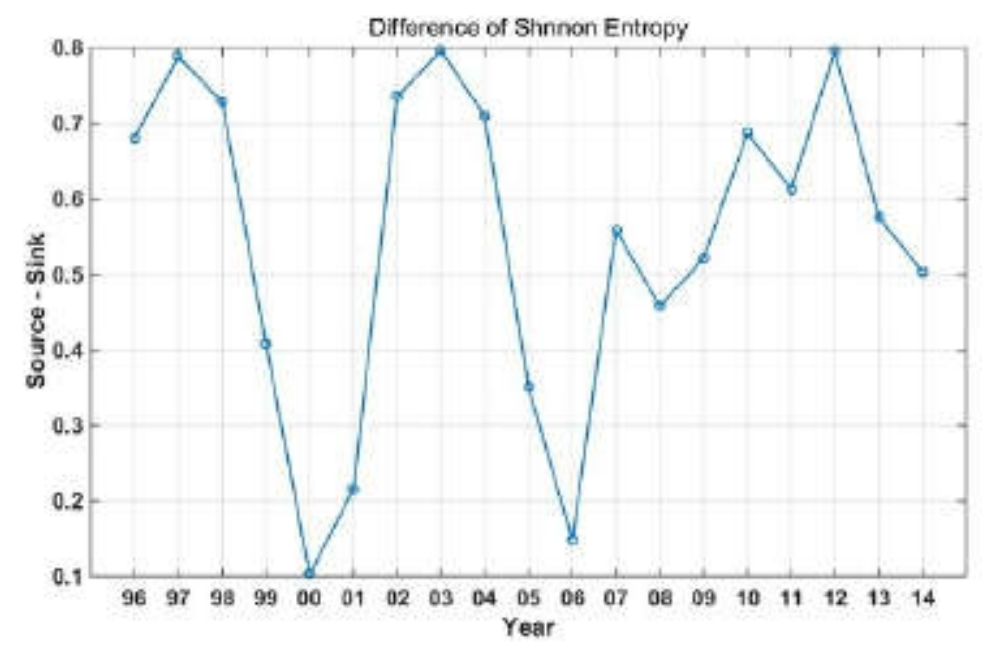

Figure 5. Difference of Shannon entropy of source and sink industries

\section{Asymmetry of SDC (ASDC) and Economic and Business Activities}

We have shown the leading role and dominance of finance industries in the U.S. economy is increasing historically. Especially from 1975 and on financial sector is the strongest source industry in the economy, in both rankings and strength once we adjust the adjacent matrix from VDM by the share of value added in the GDP and income share of financial sector in total compensation. We reinterpret the corporate finance events and investment trends from the perspective of dominance of financial sector in the economy, and propose a maxim stating that "corporate events are financial events".

In this section we show the versatility of Shannon entropy measures in identifying business cycle, and other corporate activities. Historically there are cycles in corporate events and investment trends such as M\&A activities, hot and cold IPO markets, booms and bust in internet. In additional we have seen several major financial events that rock the financial markets such as TCM debacle in 1998, Drexel Burnham Junk bond scandal in late 1980s. When the financial events have broad economy wide impact, it leads to the crises as witnessed by S\&L crisis in 1980s and 2008 financial crisis. In a broader context, we can consider the events in financial sectors as prime causes of business cycle. Interestingly, financial markets that trade securities and various asset classes coincide with business and cycles and events of corporate activities.

\subsection{Business cycle and Asymmetry of SDC (ASDC)}

The following table lists the NBER date of business cycles 
Table 1. The NBER date of business cycles

\begin{tabular}{|c|c|c|c|c|}
\hline Turning Point Date & Peak or Trough & $\begin{array}{c}\text { Announcement Dates with Links to } \\
\text { Announcement Memos. }\end{array}$ & $\begin{array}{l}\text { Local peak of } \\
\text { ASDC }\end{array}$ & $\begin{array}{l}\text { Local trough of } \\
\text { ASDC }\end{array}$ \\
\hline & & & 2012 & \\
\hline Jun-09 & Trough & September 20, 2010 & 2010 & \\
\hline Dec-07 & Peak & December 1, 2008 & & 2006 \\
\hline Nov-01 & Trough & July 17, 2003 & 2003 & \\
\hline Mar-01 & Peak & November 26, 2001 & 1997 & 2000 \\
\hline Mar-91 & Trough & December 22, 1992 & & \\
\hline Jul-90 & Peak & April 25, 1991 & 1990 & \\
\hline Nov- 82 & Trough & July 8, 1983 & & \\
\hline Jul-81 & Peak & January 6, 1982 & & \\
\hline Jul-80 & Trough & July 8, 1981 & & \\
\hline Jan-80 & Peak & June 3,1980 & 1980 & \\
\hline
\end{tabular}

Source: http://www.nber.org/cycles/cyclesmain.html.

Comparing the NBER business cycle peak/trough and the difference of Shannon entropy shows strikingly similar pattern. Local peak of the difference of Shannon entropy in 1980, 1990, 2003 and 2010 matches with business cycle peaks in 1980 and 1990, and with business trough in 2003 and 2010. The Figure 5 of Shannon entropy plots yearly observations to show the trend, and the exact date of peak and trough is not shown in the graph. The approximate synchronicity of business cycle and Shannon entropy suggests the relationship of business cycle and the connectedness of industry network. As the finance industry dominates information flows of industry network, finance industry seems to play a major role in explaining business cycle.

\section{$4.2 M \& A$ Wave and Asymmetry of SDC (ASDC)}

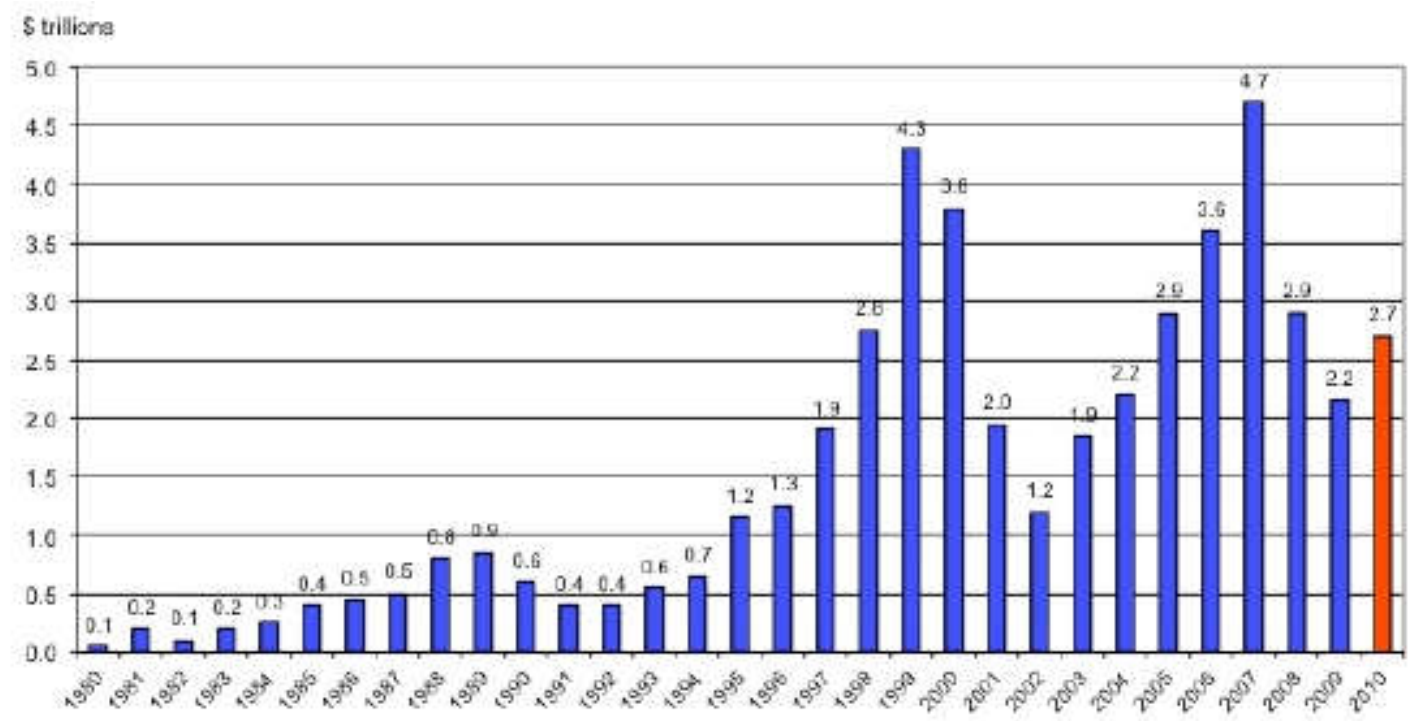

Figure 6. M\&A transaction value

Source: Stegerh and Kummer (2007).

The synchronicity of peak level of M\&A activities and Shannon entropy trough is noticeable. In addition, hostile 
takeover is more likely to be driven by financiers with the backing of financial institutions. The comparison of the trend of M\&A transaction value and the changes of ASDC in the Figure 6 reveals interesting and diametrically opposite changes. The uptrend of M\&A activities in 1996-1999 and 2002-2007 coincides with down trend of ASDC. Oppositely, the uptrend of M\&A activities in 1999-2002 and 2007-2010 corresponds to the uptrend of ASDC.

\subsection{Financialization and Securitization and Asymmetry of SDC (ASDC)}

Financialization and securitization allows trade without owning the underlying real assets. As such, these processes can be considered financial events with extensive implications on real economic activities. Tang and Xiong (2010) find that "the timing of the financial crisis did not coincide with the increase of commodity return correlations, which has already started in 2004-long before the dramatic jump-up of the VIX index in September 2008." Henderson, et al. (2015) show that banks create purely profit generating financial asset based on price changes of underlying assets in their study of CLN (commodity linked notes). In addition to financialization of commodities, securitization of assets and cash flow claims has increased dramatically in the pre-risis period. Figure 7 shows the increasing securitization in different asset class leading up to the 2008 financial crisis. Securitization market activity continues uptrend, while the ASDC start to increase in 2000 and turns to downtrend from 2003 until 2006. The difference of pattern of ASDC with M\&A transactions and securitization suggest that the real sector activities and financial transactions are not synchronized (Note 2).

Securitization Market Activity

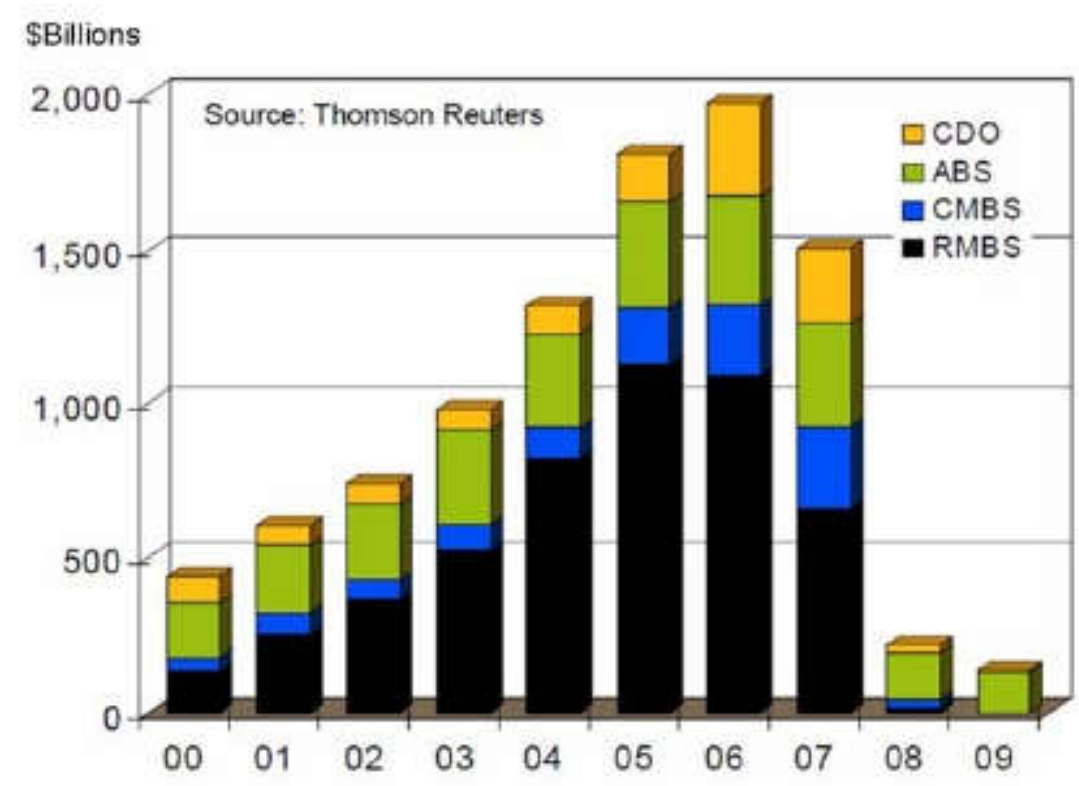

Figure 7. Securitization market activity

Source: Wikimedia Common.

\section{Conclusion and Policy Implications}

We have shown that finance industry plays a leading role in the economy for most of the sample period in a network of industries. The analysis of Shannon entropy indicates that the temporal changes in the difference of Shannon entropy of source and sink industries coincides with business cycle, corporate M\&A activities and financialization and securitization of the economy. We suggest two policy approaches in dealing with financial markets-targeted policy approach and general policy on financial markets. Cash flows are like water flows and liquidity follows higher return/risk combination and other specific nature of investor demands. As such, policy and regulatory measures targeted to specific industry are better to be devised and implemented in the context of overall connectedness of industries. More importantly, credit and liquidity channels of monetary policy should be devised to mitigate the dominance of finance industry in the economy, rather than accelerate its leading role in 
the industry networks.

\section{References}

Allen, F., Babus, A., Carletti, E. (2012). Asset commonality, debt maturity and systemic risk. Journal of Financial Economics, 104, 519-534. https://doi.org/10.1016/j.jfineco.2011.07.003

Billio, Monica, Mila Getmansky, Andrew W. Lo, \& Loriana Pelizzon. (2012). Econometric measures of connectedness and systemic risk in the finance and insurance sectors. Journal of Financial Economics, 104, 535-559. https://doi.org/10.1016/j.jfineco.2011.12.010

Cabrales, Antonio, Olivier Gossner, \& Roberto Serrano. (2013, February). Entropy and the Value of Information f Investors, America Economic Review, 103(1), 360-377

Chaney, Thomas, David Sraer, \& David Thesmar. (2012, October). The Collateral Channel: How Real Estate Shoc Affect Corporate Investment. America Economic Review, 102(6), 2381-2409. https://doi.org/10.1257/aer.102.6.2381

Chemla, G., \& Hennessy, C. A. (2014). Skin in the Game and Moral Hazard. The Journal of Finance, 69, 1597-1641. https://doi.org/10.1111/jofi.12161

Cheng, I. H., Kirilenko, A., \& W. Xiong. (2012). Convective risk flows in commodity futures markets. NBER working paper 17921. https://doi.org/10.3386/w17921

De Nicolo, Gianni, \& Marcella Lucchetta. (2010). Systemic Risks and the Macroeconomy. Internationa Monetary Fund working paper no. 29.

Diebold, F.X., \& Yilmaz, K. (2014). On the network topology of variance decompositions: Measuring the connectedness of financial firms. Journal of Econometrics, 182, 119-134. https://doi.org/10.1016/j.jeconom.2014.04.012

Ellul, A., \& Yerramilli, V. (2013). Stronger risk controls, lower risk: Evidence from US bank holding companies. The Journal of Finance, 68, 1575-1803. https://doi.org/10.1111/jofi.12057

Gan, Jie. (2007). The Real Effects of Asset Market Bubbles: Loan- and Firm-Level Evidence of a Lending Channel. Review of Financial Studies, 20, 1941-1973. https://doi.org/10.1093/rfs/hhm045

Henderson, Brian J., Neil D. Pearson, \& Li Wang. (2015). New Evidence on the Financialization of Commodity Markets. Reivew of Financial Studies, 28 (5), 1285-1311. https://doi.org/10.1093/rfs/hhu091

Jimenez, Gabriel, Steven Ongena, Jose-Luis Peydro, \& Jesus Saurina. (2012, August). Credit Supply and Moneta Policy: Identifying the Bank Balance-Sheet Channel with Loan Applications. America Economic Review, 102 (5), 2301-2326. https://doi.org/10.1257/aer.102.5.2301

Kim, Yong-Cheol Gabjin Oh. (2015). Canary in a coal mine - Analysis of Systemic Risk. Working paper.

Philippon Thomas. (2015). Has the U.S. Finance Industry Become Less Efficient? On the Theory and Measurement of Financial Intermediation. America Economic Review, 105(4), 1408-1438.

Reinhart, Carmen M., \& Kenneth S. Rogoff. (2008). Is The 2007 U.S. Subprime Crisis So Different? An International Historical Comparison. American Economic Review, 98(2), 339-344. https://doi.org/10.1257/aer.98.2.339

Steger, Ulrich, \& Christopher Kummer. (2007). Why Merger and Acquisition (M\&A) Waves Reoccur - The Vicious Circle from Pressure to Failure. Working paper, IMD 2007-11.

Tang, K., \& W. Xiong. (2012). Index investing and the financialization of commodities. Financial Analysts Journal, 68(6), 54-74. https://doi.org/10.2469/faj.v68.n6.5

Williamson, Stephen D. (2012, October). Liquidity, Monetary Policy, and the Financial Crisis: A New Monetarist Approach. America Economic Review, 102(6), 2570-2605. https://doi.org/10.1257/aer.102.6.2570

\section{Notes}

Note 1. http://mba.tuck.dartmouth.edu/pages/faculty/ken.french/Data_Library/det_30_ind_port.html

We assign each NYSE, AMEX, and NASDAQ stock to an industry portfolio at the end of June of year $t$ based on its four - digit SICcode at that time. (We use Compustat SIC codes for the fiscal year ending in calendar year $\mathrm{t}$ 1. Whenever Compustat SIC codes are not available, we use CRSP SIC codes for June of year t.) We then compute returns from July of $t$ to June of $t+1$.] 
Note 2. This point deserves further investigation and analysis.

\section{Appendix}

The network defined by variance decomposition matrix, where the entries are weights, and directed as the strength of information flows from industry $i$ to $j$ is not the same as strength of information flows from industry $j$ to $i$. The sum of rows of the adjacent matrix is 1 as the entries are variance shares.

The network connectedness is estimated by the following steps.

First, we estimated network structure by variance decomposition.

$$
\begin{gathered}
G I_{Y}\left(n, \delta_{j}, \Omega_{t-1}\right)=E\left(Y_{t+n} \mid \varepsilon_{j t}=\delta_{j}, \Omega_{t-1}\right)-E\left(Y_{t+n} \mid \Omega_{t-1}\right) \\
\psi_{j}^{g}(n)=\sigma_{j j}^{-\frac{1}{2}} A_{n} \sum e_{j}, n=0,1,2 \ldots,
\end{gathered}
$$

Denoting the generalized forecast error variance decompositions by $\theta_{i j}^{g}(n) \mathrm{n}=0,1,2, \ldots$,

$$
\theta_{i j}^{g}(n)=\frac{\sigma_{i i}^{-1} \sum_{l=0}^{n}\left(e_{i}^{\prime} A_{l} \Sigma e_{j}\right)^{2}}{\sum_{l=0}^{n}\left(e_{i}^{\prime} A_{l} \Sigma A_{l}^{\prime} e_{i}\right)}, i, j=1, \ldots, m .
$$

Notice that by construction $\sum_{j=1}^{m} \theta_{i j}^{o}(n)=1$. However, due to the non-zero covariance between the original (non-orthogonalized) shocks, in general $\sum_{j=1}^{m} \theta_{i j}^{g}(n) \neq 1$.

$$
\begin{gathered}
\tilde{\eta}_{i j}(n)=\frac{\theta_{i j}^{g}(n)}{\sum_{j=1}^{m} \theta_{i j}^{g}(n)}(\text { Normalized GVD }) \\
\sum_{j=1}^{m} \tilde{\eta}_{i j}(n)=1, \sum_{i=1}^{m} \sum_{j=1}^{m} \tilde{\eta}_{i j}(n)=m,
\end{gathered}
$$

$\mathrm{m}=$ the number of variables, where I and $\mathrm{J}$ denotes industry.

Second, we capture the asymmetric information flows based on variance decomposition adjacent matrix. General feature of variance decomposition matrix (adjacent matrix) applying network theory has the following the characteristics. Sum of each row equals to one as we use weights in the matrix.

\begin{tabular}{ccccccc}
\hline & $\mathrm{A}$ & $\mathrm{B}$ & $\mathrm{C}$ & $\mathrm{D}$ & $\mathrm{E}$ & $\mathrm{F}$ \\
\hline $\mathrm{A}$ & 0.5 & 0.1 & 0.2 & 0.05 & 0.05 & 0.1 \\
$\mathrm{~B}$ & 0.2 & 0.4 & 0.05 & 0.15 & 0.1 & 0.1 \\
$\mathrm{C}$ & 0.25 & 0.01 & 0.6 & 0.05 & 0.04 & 0.15 \\
$\mathrm{D}$ & 0.01 & 0.05 & 0.02 & 0.8 & 0.02 & 0.1 \\
$\mathrm{E}$ & 0.2 & 0.05 & 0.15 & 0.03 & 0.5 & 0.07 \\
$\mathrm{~F}$ & 0.1 & 0.1 & 0.1 & 0.13 & 0.07 & 0.4 \\
\hline
\end{tabular}

The diagonal term shows effects of own variance, and off-diagonal terms are pairwise variance decomposition with respect to other entrants.

We define the asymmetric strength (weighted), directed connectedness (ASDC). 


$$
\operatorname{ASDC}(i)=\sum_{j, j \neq i} \frac{\text { Industry }_{i \rightarrow j}-\text { Industry }_{j \rightarrow i}}{\text { Indry } y_{i \rightarrow j}+\text { Industry }_{j \rightarrow i}}
$$

We identify the source and sink based on the ASDC - an industry with ASDC $>0$ plays a role of source in information flow network, while if ASDC $<=0$, it is considered as sink. To capture ASDC, first, we calculate an information flows among industries using the VDM approach, and we remove diagonal terms of information flow matrix to consider interdependence among industries as significant factors systemic risk. At each sub-period (approximately 5 years), we estimate the ASDC to observe the source-sink relation.

\section{Copyrights}

Copyright for this article is retained by the author(s), with first publication rights granted to the journal.

This is an open-access article distributed under the terms and conditions of the Creative Commons Attribution license (http://creativecommons.org/licenses/by/4.0/). 